DOI: $10.19113 /$ sdufenbed.471075

\title{
Pomza'nın Fiziksel Özelliklerinin Kuru Birim Hacim Ağırlığı ve Termal İletkenliği Üzerine Etkileri
}

\author{
Savaş ÖZÜN \\ Süleyman Demirel Üniversitesi, Mühendislik Fakültesi, Maden Mühendisliği Bölümü, 32260, Isparta, Türkiye \\ (ORCID: https://orcid.org/0000-0001-9475-1822)
}

(Alınış / Received: 16.10.2018, Kabul / Accepted: 19.11.2018, Online Yayınlanma / Published Online: 04.03.2019)

\author{
Anahtar Kelimeler \\ Pomza, \\ Tane boyutu, \\ Yoğunluk, \\ Kuru birim hacim ağırlık, \\ Termal iletkenlik
}

\begin{abstract}
Özet: $\mathrm{Bu}$ çalışmada, pomzada tane boyutu ve yoğunluğunun kuru birim hacim ağırlığı (gevşek) değeri üzerine etkilerinin belirlenmesi amaçlanmıştır. Çalışma ayrıca, farklı özgül ağırlıklara sahip olan pomza numuneleri kullanılarak hazırlanan yapı bloklarının termal iletkenliklerini de araştırmayı amaçlamıştır. Yapılan testlerde, Isparta bölgesi, Türkiye'den temin edilen pomza örneği, $4.75 \mathrm{~mm}$ ile $50 \mathrm{~mm}$ arasında dört farklı boyutta sınıflandırılmış. Her bir boyuttaki pomza numunesi, farklı yoğunluklarda pomza örneklerinin elde edilmesi amacıyla 1.2 $\mathrm{g} / \mathrm{cm}^{3}$ ve $1.8 \mathrm{gr} / \mathrm{cm}^{3}$ arasında, çinko klorür $\left(\mathrm{ZnCl}_{2}\right)$ kullanılarak hazırlanan ağır ortam sıvılarında laboratuvar ölçekli yüzdürme-batırma testlerine tabi tutulmuştur. Sonuçlar, kuru birim hacim ağırlık değerlerinin pomza numunelerinin yoğunluğuna ve tane boyutuna bağlı olarak değiștiğini; yüksek yoğunluklu pomza numuneleri ile karşılaştırıldığında düşük yoğunluklu pomza numunelerinin daha düşük kuru birim hacim ağırlık değerleri sergilediğini göstermiştir. Buna ek olarak, küçülen tane boyutu ve artan pomza yoğunluğu ile birlikte kuru birim hacim ağırlık değerlerinin arttığı belirlenmiştir. Sonuçlar ayrıca, düşük yoğunluklu pomza örnekleri kullanılarak hazırlanan yapı bloklarının, yüksek yoğunluklu pomza örnekleri ile hazırlanan yapı bloklarından daha iyi ısı iletkenliği sağladığını göstermiştir.
\end{abstract}

\section{Influences of Physical Properties of Pumice on Its Dry Unit Volume Weight and Thermal Conductivity}

\section{Keywords}

Pumice,

Particles size,

Density,

Dry unit volume weight,

Thermal conductivity

\begin{abstract}
This study aimed to determine the influences of particle size and density of pumice on its dry unit volume weight (loose) values. The study also aimed to investigate the thermal conductivities of building blocks prepared using pumice samples having different specific gravities. For the tests, as-received pumice sample, obtained from Isparta province, Turkey, was classified in four different size fractions between $4.75 \mathrm{~mm}$ and $50 \mathrm{~mm}$. Each sized pumice sample was subjected to laboratory scale float-sink tests in heavy medium liquids, prepared using zinc chloride $\left(\mathrm{ZnCl}_{2}\right)$, between $1.2 \mathrm{~g} / \mathrm{cm}^{3}$ and $1.8 \mathrm{~g} / \mathrm{cm}^{3}$ in order to get pumice samples with different densities. The results showed that dry unit volume weight (loose) values of pumice samples varied depending on the density and particle size of pumice samples. The pumice samples having lower densities and bigger particle sizes displayed lower dry unit volume weight values, compared to those of higher densities and smaller particle sizes. The results also showed that building blocks prepared using pumice samples having lower densities provided better thermal conductivities than high-density pumice samples.
\end{abstract}

\section{Giriş}

Açlk renkli, hafif ve yüksek silis içerikli volkanik bir kayaç olan pomza, magmanın volkanik püskürme esnasında hızla soğumasına ve basıncın hızla düşmesine bağlı olarak bünyesindeki çözünmüş gazların ve suyun eriyikten hızla uzaklaşması neticesinde gözenekli bir özellik kazanmaktadır.
Volkanın püskürme şiddeti ve pomzanın gözeneklilik derecesi magmadaki artan çözünmüş gaz miktarı ile artarken, püskürme sonucu oluşan ince boyutlu olanlar pümisit (pumicite), iri boyutlu olanları ise pumis (pumice) ya da pomza adını almaktadır [1]. Bir kristal yapısı olmadığı için cam olarak kabul edilen pomza, ortalama 1-2 özgül ağırlığa ve 5-6 Mohs sertlik değerine sahiptir [2-4]. Gözenekler arası camsı 
bir zarla ayrılan pomzanın gözeneklilik oranı \%70'lere kadar çlkabilmekte ve makro boyutlardan mikro boyutlara kadar geniş bir boyut dağılımı göstermektedir [5].

Pomza süngerimsi gözenekli yapısına bağlı olarak düşük özgül ağırlı özelliği göstermektedir. Birbirlerinden camsı zarlar ile ayrlan düzensiz ve küresel, oval ve uzamış boru şeklinde olabilen gözenekli yapı pomzaya sese, ısıya ve soğuya karşı çok iyi bir yalıtım özelliği kazandırmaktadır [6, 7]. Ayrıca ateșe ve neme dayanaklılı̆̆l, yüksek basınç mukavemeti, normal betonla karşılaştırıldığında pomzalı betonun deprem yüklerine karşı daha elastik davranış gösterebilmesi ve pomza içerikli beton/yapı elemanlarının dona karşı dayanıklı olması vb. özellikleri nedeniyle madenciliği yapılan pomzanın yaklaşık \%80'i inşaat sektöründe kullanılmaktadır $[8,9]$.

Pomzanın inşaat sektöründe kullanımı çoğunlukla hafif tuğlalar, bloklar (bims vb.), asmolenler, paneller vb. şeklindedir. Yüksek puzzolanik özelliğe sahip pomza katkılı beton kullanımı ile betonun hafif olması, dolayısıyla bina yüklerinin önemli ölçüde azalması sağlanmaktadır. Normal kum/çakılın özgül ağırlıkları ile karşılaştırıldığında pomza kullanımı ile yaklaşık 1/3-2/3 oranında daha az özgül ağırlıklı beton eldesi sağlamaktadır [10]. Fiziksel özelliklerine ek olarak pomza kimyasal olarak da inert (tesirsiz) özellik sergilemektedir [11].

Pomza doğada genellikle andezit, bazalt ve traverten ile birlikte bulunmakla birlikte, pomza rezervleri az miktarda plajiyoklas ve alkali feldispatlar, piroksen, olivin, mika, amfibol ve kuvars da içermektedirler [12]. Pomza ile karşılaştırıldığında gözenekli bir yapısal özellik sergilemeyen ve daha yüksek yoğunluklara $\left(2-4.5 \mathrm{gr} / \mathrm{cm}^{3}\right)$ sahip olan bu minerallerin varlığı, elde edilen ürünün yalıtım özelliğini düşürürken, birim hacim ağırlığını da artırmaktadır. Bu sebeple, mekanik kazı yöntemleri ile açık işletme madenciliği uygulanarak üretimi gerçekleştirilen ve kazı işlemleri sonrasında herhangi bir zenginleștirme işlemine tabi tutulmadan çoğunlukla eleme işlemleri ile boyuta göre sınıflandırılmakta olan pomza kalitesinin artırılması için cevherden bu minerallerin uzaklaştırılması gerekmektedir.

Bu bağlamda bu çalışma kapsamında Isparta, Gelincik bölgesinden temin edilen ve $4.75 \mathrm{~mm}$ ile $50 \mathrm{~mm}$ arasında 4 farklı boyut aralığında sinıflandırılan tüvenan pomza numunesinin tane boyutuna ve yoğunluğuna bağlı olarak kuru birim hacim ağırlıklarına olan etkileri incelenmiştir. Çalışma ayrıca farklı yoğunluklara sahip pomza numuneleri kullanılarak elde edilen yapı bloklarının termal iletkenlik değerlerinin belirlenmesini de amaçlamıştır.

\section{Malzeme ve Yöntem}

Tüvenan pomza numunesi, Gelincik bölgesi, Isparta'da faaliyet gösteren ISBAŞ Bimsblok A.Ş.'den temin edilmiştir. $50 \mathrm{~mm}$ 'den daha ince boyut dağılımına ve yaklaşık $642 \mathrm{~kg} / \mathrm{m}^{3} \mathrm{kuru}$ birim hacim ağırlık değerine sahip olan tüvenan pomza numunesinin X-ışını floresans (XRF) analizi sonuçları \% $60 \mathrm{SiO}_{2}, \% 17.8 \mathrm{Al}_{2} \mathrm{O}_{3}, \% 4.7 \mathrm{Fe}_{2} \mathrm{O}_{3}, \% 2.7 \mathrm{MgO}, \% 8$ $\mathrm{Na}_{2} \mathrm{O}+\mathrm{K}_{2} \mathrm{O}$ ve $\% 5 \mathrm{CaO}$ olarak belirlenmiştir.

Deneysel çalışmalar öncesinde pomza numunesi öncelikli olarak -50+25 mm, -25+15 mm, -15+10 mm ve $-10+4.75 \mathrm{~mm}$ tane boyutu aralıklarında sınıflandırılmıştır. Her bir dar tane boyutu aralığında elde edilen pomza numuneleri daha sonra ayrı ayrı laboratuvar ölçekli yüzdürme-batırma testlerine tabi tutulmuştur. Yüzdürme-batırma testlerinde kullanılan 1.2-1.8 gr $/ \mathrm{cm}^{3}$ yoğunlukları arasında 0.1 $\mathrm{gr} / \mathrm{cm}^{3}$ 'lük artış oranına sahip (Şekil 1) ağır sıvılar çinko klorürün $\left(\mathrm{ZnCl}_{2}\right)$ suda çözünmesi ile hazırlanmıştır. Ağır sıvıların yoğunlukları her bir test öncesinde tekrar kontrol edilmiş, yoğunluk değerleri değişen sıvıların yoğunlukları çinko klorür ilavesi ile tekrar ayarlanmıştır. Testler sonrasında her bir yoğunlukta elde edilen pomza (yüzen) numuneleri süzgeç yardımıyla ayrı ayrı alınarak tanelerin yüzeylerini kaplayan çinko klorür çözeltisinin uzaklaştırılması amacıyla yıkanmış, süzülmüş ve $100^{\circ} \mathrm{C}^{\prime}$ de etüvde kurumaya bırakılmıștır.



Şekil 1. Laboratuvar ölçekli yüzdürme-batırma test düzeneğinin şematik görüntüsü. 
Çoğunlukla yoğunluk, kütle yoğunluğu veya birim kütlesi olarak adlandırılan birim hacim ağırlığı; kapasitesi $\mathrm{kg} / \mathrm{m}^{3}$ olarak ifade edilen bir kabı dolduran kuru numunenin ağırlığı olarak tanımlanır. $\mathrm{Bu}$ çalışma kapsamında her bir boyut aralığındaki pomza numunelerinin (farklı yoğunluklarda) kuru birim hacim ağırlıkları, uygun boyuttaki bir ölçü silindirine (mezür) tartılmış bir kısmının yerleştirilmesi ve kaplanan hacmin belirlenmesi yoluyla hesaplanmıştır. Hesaplamalar her bir değişken için 2 numune hazırlanarak gerçekleştirilmiş, aritmetik ortalama değeri nihai birim hacim ağırlığı değeri olarak kabul edilmiştir. Tüvenan pomza numunesinin her bir dar tane boyutu aralığındaki \% miktarları ve kuru birim hacim ağırlık değerleri Tablo 1'de verilmiştir. Sonuçlara göre tüvenan pomza numunesinin yaklaşık \%68'inin 15 mm'den daha iri boyutlu olduğu ve kuru birim hacim ağırlıklarının küçülen tane boyutu ile ters orantılı olarak arttı̆̆ı görülmektedir.

Tablo 1. Tüvenan pomza numunesinin tane boyu dağılımına bağlı kuru birim hacim ağırlık değerleri.

\begin{tabular}{ccc}
\hline $\begin{array}{c}\text { Tane Boyutu } \\
(\mathrm{mm})\end{array}$ & $\begin{array}{c}\% \\
\text { Ağılık }\end{array}$ & $\begin{array}{c}\text { Birim Hacim A Ăırlı̆̆ } 1 \\
(\mathrm{kuru})\left(\mathrm{kg} / \mathrm{m}^{3}\right)\end{array}$ \\
\hline$-50+25$ & 32.41 & 643.08 \\
$-25+15$ & 35.22 & 583.56 \\
$-15+10$ & 12.93 & 649.85 \\
$-10+4.75$ & 9.28 & 717.04 \\
-4.75 & 10.16 & 762.10 \\
\hline
\end{tabular}

Gerçekleştirilen yüzdürme-batırma testleri sonucunda elde edilen her bir farklı yoğunluğa sahip pomza numuneleri kullanarak hazırlanan yapı bloklarının hazırlanma işlemleri 10x10x10 $\mathrm{cm}^{3}$ hacimli kalıplarda Çelik Makina markalı beton presi (Şekil 2 (a)) ile $25 \mathrm{MPa}$ basınç uygulanarak gerçekleştirilmiştir. Cihaz aynı zamanda tek eksenli basma ve dolaylı çekme dayanımı yapma kabiliyetine sahip olmakla birlikte max 200 ton yükleme kapasitesi sağlamaktadır. Termal iletkenlik değerleri ise EN 1946-2'ye uygun olarak ISBAŞ A.Ş. laboratuvarlarında $<1 \%$ hata payına sahip yüksek hassasiyet ve doğruluk ile ölçüm işlemleri gerçekleştiren Lambda-Messtechnik GmbH Dresden, Lambda Meter EP500e (Şekil 2 (b)) ile belirlenmiştir.
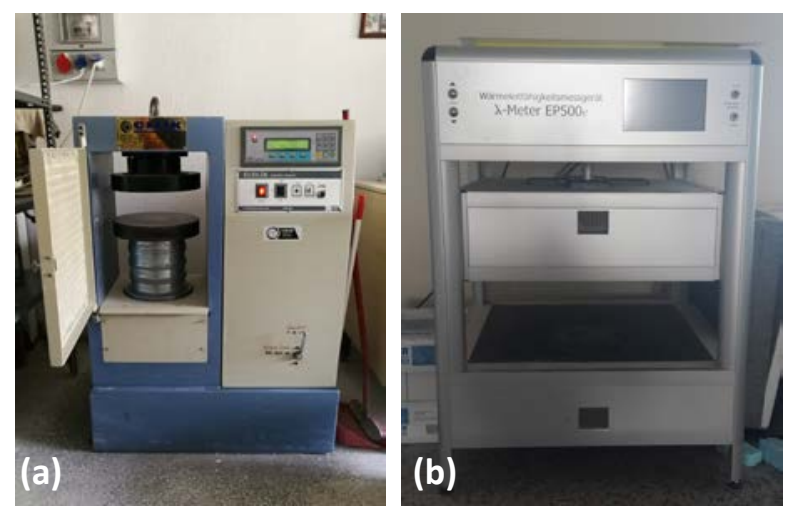

Şekil 2. Çalışmalarda kullanılan (a) Tek eksenli basınç dayanımı test cihazı ve (b) Termal iletkenlik ölçer, Lambda Meter EP500e

\section{Deneysel Sonuçlar}

Çalışmanın bu bölümünde tane boyutuna göre sinıflandırılmış pomza numuneleri ile gerçekleștirilen yüzdürme-batırma test sonuçları, farklı yoğunluklara sahip pomza numunelerinin kuru birim hacim ağırlık değerleri ve pomza numuneleri kullanılarak hazırlanan yapı bloklarının termal iletkenlik değerleri verilmiştir. Birim hacim ağırlı belirlemeleri için sonuçlar azalan tane boyutu dağılımına göre alt bașlıklar halinde sunulmuştur.

\section{1. $-50+25 \mathrm{~mm}$ tane boyutlu pomza numunesinin yoğunluğa dayalı kuru birim hacim ağırlıklarının belirlenmesi}

Tablo 2'de $-50+25 \mathrm{~mm}$ tane boyutu aralığında sınıflandırılmış pomza numunesi ile gerçekleștirilen yüzdürme-batırma test sonuçları ile elde edilen her bir yoğunluk için \% ağırlıkça numune miktarları ve Şekil 3'de her bir yoğunluktaki pomza numunelerinin kuru birim hacim ağırlıkları grafiksel olarak verilmiştir. Sonuçlara göre beslemenin yaklaşık \% 37'si $1.8 \mathrm{gr} / \mathrm{cm}^{3}$ 'den daha ağır malzeme olarak alınırken, yaklaşık \% 11.2'lik kısmı ise $1.2 \mathrm{gr} / \mathrm{cm}^{3}$ 'den daha hafif malzeme olarak yüzün ürün olarak alınmıştır.

Dolayısıyla $1.2 \mathrm{gr} / \mathrm{cm}^{3}$ de yüzen pomza numunesinin kuru birim hacim ağırlık değeri $360 \mathrm{~kg} / \mathrm{m}^{3}$ iken, artan yoğunlukla birlikte pomza numunelerinin kuru birim hacim ağırlık değerleri kademeli olarak artarak 1.5 $\mathrm{gr} / \mathrm{cm}^{3}$ 'de yüzen pomza numunesi için $560 \mathrm{~kg} / \mathrm{m}^{3} \mathrm{e}$, $1.8 \mathrm{gr} / \mathrm{cm}^{3}$ 'de yüzen pomza numunesi için 700 $\mathrm{kg} / \mathrm{m}^{3^{\prime}}$ e ve $1.8 \mathrm{gr} / \mathrm{cm}^{3}$ 'de batan pomza numunesi için ise $1000 \mathrm{~kg} / \mathrm{m}^{3}$ e çıاkmaktadır.

Tablo 2. $-50+25 \mathrm{~mm}$ tane boyutu aralığında sınıflandırılmıș pomza numunesinin yüzdürme-batırma test sonuçları

\begin{tabular}{|c|c|c|}
\hline \multicolumn{2}{|c|}{$\begin{array}{l}\text { Yoğunluk } \\
\left(\mathrm{gr} / \mathrm{cm}^{3}\right)\end{array}$} & $\begin{array}{c}\text { Ağırlık } \\
(\%)\end{array}$ \\
\hline Yüzen & 1.2 & 11.17 \\
\hline 1.2 & 1.3 & 18.46 \\
\hline 1.3 & 1.4 & 16.00 \\
\hline 1.4 & 1.5 & 8.67 \\
\hline 1.5 & 1.6 & 1.84 \\
\hline 1.6 & 1.7 & 4.00 \\
\hline 1.7 & 1.8 & 3.06 \\
\hline 1.8 & Batan & 36.80 \\
\hline \multicolumn{2}{|c|}{ Besleme } & 100.00 \\
\hline
\end{tabular}

\section{2. $-25+15 \mathrm{~mm}$ tane boyutlu pomza numunesinin yoğunluğa dayalı kuru birim hacim ağırlıklarının belirlenmesi}

Tüvenan cevherin yaklașık \% 35'ini oluşturan ve deneysel çalıșmalarda kullanılan ikinci en iri boyut aralığı olan, $-25+15$ mm'de boyuta göre sınıflandırılmış pomza numunesi kullanılarak elde edilen yüzdürme-batırma test sonuçları ve numunelerin yoğunluğa bağlı kuru birim hacim 
ağırlık değerleri sırasıyla Tablo 3 ve Şekil 4'de verilmiştir. Sonuçlara göre, beslemenin yaklaşık \% 30 'u $1,8 \mathrm{gr} / \mathrm{cm}^{3}$ 'den daha ağır malzeme olarak alınırken, yaklaşık \% 7'si ise yüzdürme-batırma testlerinde elde edilen en az yoğunluklu malzeme olarak $1.2 \mathrm{gr} / \mathrm{cm}^{3}$ lik ağır sıvıda yüzen pomza numunesi olarak elde edilmiștir.



Şekil 3. $-50+25 \mathrm{~mm}$ tane boyutu aralığında sınıflandırılmıș pomza numunesinin yoğunluğa dayalı birim hacim ağırlık değerleri

Tablo 3. - 25+15 mm tane boyutu aralığında sınıflandırılmış pomza numunesinin yüzdürme-batırma test sonuçları

\begin{tabular}{|c|c|c|}
\hline \multicolumn{2}{|r|}{$\begin{array}{l}\text { Yoğunluk } \\
\left(\mathrm{gr} / \mathrm{cm}^{3}\right)\end{array}$} & $\begin{array}{c}\text { Ağırlık } \\
(\%)\end{array}$ \\
\hline Yüzen & 1.2 & 7.06 \\
\hline 1.2 & - 1.3 & 16.21 \\
\hline 1.3 & - $\quad 1.4$ & 18.66 \\
\hline 1.4 & - 1.5 & 16.35 \\
\hline 1.5 & - 1.6 & 4.74 \\
\hline 1.6 & - $\quad 1.7$ & 4.44 \\
\hline 1.7 & - 1.8 & 2.67 \\
\hline 1.8 & Batan & 29.88 \\
\hline & Besleme & 100.00 \\
\hline
\end{tabular}

Kuru birim hacim ağırlıklarının pomzanın gözeneklilik oranı ile ters orantılı olduğu, artan gözeneklilik oranı ile birlikte elde edilen numunelerin birim hacim ağırlıklarının azaldığı görülmektedir. Bu nedenle tüvenan cevherde aynı boyut aralığı için elde edilen yaklaşık $585 \mathrm{~kg} / \mathrm{m}^{3}$ lük kuru birim hacim ağırlığı değeri ile karşılaştırıldığında, $1.2 \mathrm{gr} / \mathrm{cm}^{3}$ yoğunluklu çinko klorür çözeltisinde yüzen pomza numunesinin birim hacim ağırlığı yaklaşık \% 40'lık bir azalma ile $347 \mathrm{~kg} / \mathrm{m}^{3} \mathrm{e}$ düşmektedir.

Artan malzeme yoğunluğu ile birim hacim ağırlıkları kademeli olarak artarak; $1.3 \mathrm{gr} / \mathrm{cm}^{3}$ de yüzen pomza numunesi için $370 \mathrm{~kg} / \mathrm{m}^{3} \mathrm{e}, 1.5 \mathrm{gr} / \mathrm{cm}^{3} \mathrm{de}$ yüzen pomza numunesi için $460 \mathrm{~kg} / \mathrm{m}^{3} \mathrm{e}, 1.7 \mathrm{gr} / \mathrm{cm}^{3} \mathrm{de}$ yüzen pomza numunesi için $600 \mathrm{~kg} / \mathrm{m}^{3} \mathrm{e}$ ve 1.8 $\mathrm{gr} / \mathrm{cm}^{3}$ de yüzen pomza numunesi için ise 750 $\mathrm{kg} / \mathrm{m}^{3}$ e ulaşmaktadır. $1.8 \mathrm{gr} / \mathrm{cm}^{3}$ de batan pomza numunesinin birim hacim ağırlı̆g ise bu boyut aralığında elde edilen en yüksek değer olan 910 $\mathrm{kg} / \mathrm{m}^{3^{\prime} \mathrm{e}}$ kadar yükselmektedir.

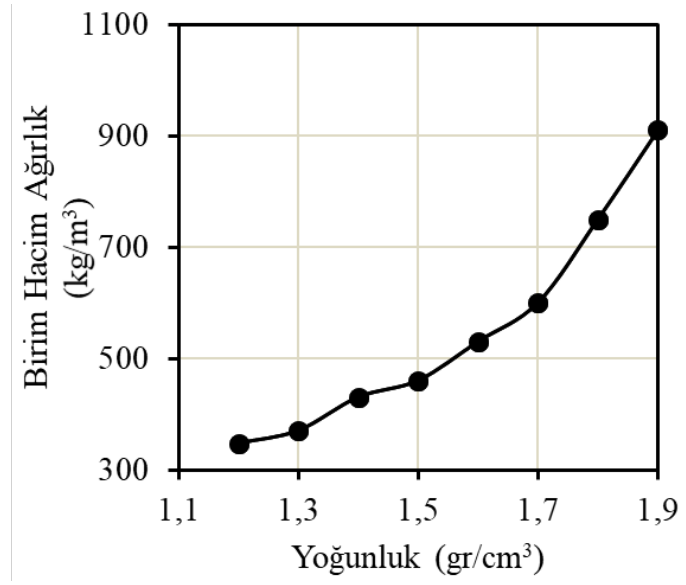

Şekil 4. -25+15 mm tane boyutu aralığında sınıflandırılmış pomza numunesinin yoğunluğa dayalı birim hacim ağırlık değerleri

\section{3. -15+10 mm tane boyutlu pomza numunesinin yoğunluğa dayalı kuru birim hacim ağırlıklarının belirlenmesi}

Tablo 4 ve Şekil 5'de verilen sonuçlara göre küçülen tane boyut dağılımı ile birlikte pomza numunelerinin gözeneklilik oranları azalmakta, böylece daha iri boyutlara kısayla $1.2 \mathrm{gr} / \mathrm{cm}^{3}$ ve $1.3 \mathrm{gr} / \mathrm{cm}^{3}$ yoğunlukta yüzen ürün olarak elde edilen pomza numunesinin miktarı azalmaktadır. $1.2 \mathrm{gr} / \mathrm{cm}^{3}$ yoğunluklu çinko klorür çözeltisinde beslemenin yalnızca \%1.2'si yüzen ürün olarak alınırken, bu değer $1.3 \mathrm{gr} / \mathrm{cm}^{3}$ yoğunluk için yaklaşık olarak \%6.2'ye çıkmaktadır. Belirtilen yoğunluklar için birim hacim ağırlıkları ise sırasıyla $343 \mathrm{~kg} / \mathrm{m}^{3}$ ve 390 $\mathrm{kg} / \mathrm{m}^{3}$ olarak belirlenmiștir. Daha iri tane boyutlarında siniflandırılan pomza numunelerinin birim hacim değerlerinde olduğu gibi, $-15+10 \mathrm{~mm}$ tane boyutunda sinıflandırılmış pomza numunesinin birim hacim ağırlı̆̆ değerleri de yoğunlukla doğru orantılı olarak artmaktadır. Elde edilen sonuçlara göre \%12.5'i $1.6 \mathrm{gr} / \mathrm{cm}^{3}$ yoğunluklu çinko klorür çözeltisinde yüzen ürün olarak alınan pomza numunesinin birim hacim ağırlı̆̆ $510 \mathrm{~kg} / \mathrm{m}^{3}$ iken, bu değer $1.8 \mathrm{gr} / \mathrm{cm}^{3}$ yoğunlukta yüzen pomza numunesi için $730 \mathrm{~kg} / \mathrm{m}^{3} \mathrm{e}$ çıkmaktadır.

Tablo 4. - $15+10 \mathrm{~mm}$ tane boyutu aralığında sınıflandırılmış pomza numunesinin yüzdürme-batırma test sonuçları

\begin{tabular}{|c|c|c|}
\hline \multicolumn{2}{|c|}{$\begin{array}{l}\text { Yoğunluk } \\
\left(\mathrm{gr} / \mathrm{cm}^{3}\right)\end{array}$} & $\begin{array}{c}\text { Ağırlık } \\
(\%)\end{array}$ \\
\hline Yüzen & 1.2 & 1.18 \\
\hline 1.2 & 1.3 & 6.15 \\
\hline 1.3 & 1.4 & 12.76 \\
\hline 1.4 & 1.5 & 22.13 \\
\hline 1.5 & 1.6 & 12.52 \\
\hline 1.6 & 1.7 & 6.17 \\
\hline 1.7 & 1.8 & 3.99 \\
\hline 1.8 & Batan & 35.10 \\
\hline \multicolumn{2}{|c|}{ Besleme } & 100.00 \\
\hline
\end{tabular}




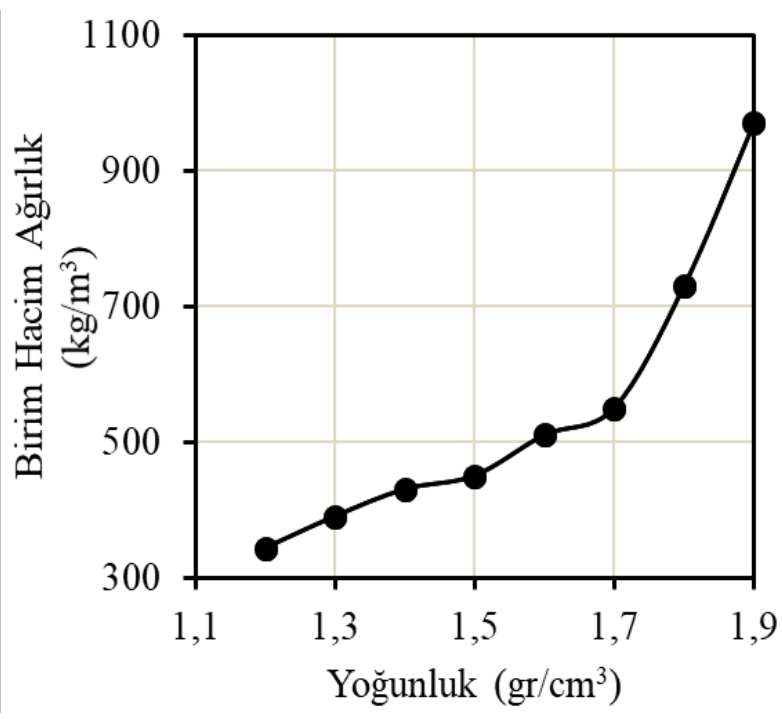

Şekil 5. $-15+10 \mathrm{~mm}$ tane boyutu aralığında sınıflandırılmıș pomza numunesinin yoğunluğa dayalı birim hacim ağırlık değerleri

3.4. $-10+4.75 \mathrm{~mm}$ tane boyutlu pomza numunesinin yoğunluğa dayalı kuru birim hacim ağırlıklarının belirlenmesi

Pomzaların tane boyutları küçüldükçe ilişkili gang minerallerinden serbestleşme dereceleri artmaktadır. Ancak bu durum, özellikle pomza tanelerinin çoğunlukla makro gözeneklerden oluşması durumunda gözeneklilik oranını olumsuz olarak etkilemektedir. $-10+4.75 \mathrm{~mm}$ pomza numunesi (Tablo 5) kullanılarak elde edilen sonuçlar, besleme numunesinin \% 50'den fazlasının 1.4-1.6 gr/cm ${ }^{3}$ yoğunluklu çinko klorür çözeltilerinde yüzen malzeme olarak alındığını göstermiştir.

Belirtilen yoğunluklardan daha düşük yoğunluklarda ise yüzen pomza numunesi elde edilemezken, besleme malzemesinin yaklaşı \%37'si ise 1.8 $\mathrm{gr} / \mathrm{cm}^{3}$ lük çinko klorür çözeltisinde batan malzeme olarak alınmıştır. Bu boyutta en düşük birim hacim ağırlığı $1.4 \mathrm{gr} / \mathrm{cm}^{3}$ de yüzen pomza numunesi için $380 \mathrm{~kg} / \mathrm{m}^{3}$ olarak hesaplanmıștır (Şekil 6).

Tablo 5. $-10+4.75 \mathrm{~mm}$ tane boyutu aralığında sinıflandırılmış pomza numunesinin yüzdürme-batırma test sonuçları

\begin{tabular}{|c|c|c|}
\hline \multicolumn{2}{|c|}{$\begin{array}{l}\text { Yoğunluk } \\
\left(\mathrm{gr} / \mathrm{cm}^{3}\right)\end{array}$} & $\begin{array}{l}\text { Ağırlık } \\
(\%)\end{array}$ \\
\hline Yüzen & 1.2 & 0 \\
\hline 1.2 & 1.3 & 0 \\
\hline 1.3 & 1.4 & 0.95 \\
\hline 1.4 & 1.5 & 10.88 \\
\hline 1.5 & 1.6 & 37.98 \\
\hline 1.6 & 1.7 & 5.33 \\
\hline 1.7 & 1.8 & 7.89 \\
\hline 1.8 & Batan & 36.97 \\
\hline \multicolumn{2}{|c|}{ Besleme } & 100.00 \\
\hline
\end{tabular}

\subsection{Termal iletkenlik analizleri}

Yapı blokları üretiminde normal agregalar yerine pomza, perlit vb. gözenekli minerallerin kullanımı ile hafif normal agregalarla üretilmiş yapı bloklarıyla karşılaştırıldığında hem ağırlık bakımında hem de termal yalıtım açısından çeşitli avantajların sağladığı bilinmektedir [13-16]. Ancak, bu çalışma kapsamında gerçekleştirilen yüzdürme-batırma test sonuçlarına göre pomza aynı ocaktan üretimi gerçekleştirilmiş numunede her bir dar tane boyutu aralığında farklı yoğunluklara sahip pomza tanelerinin bulunduğu görülmüștür.

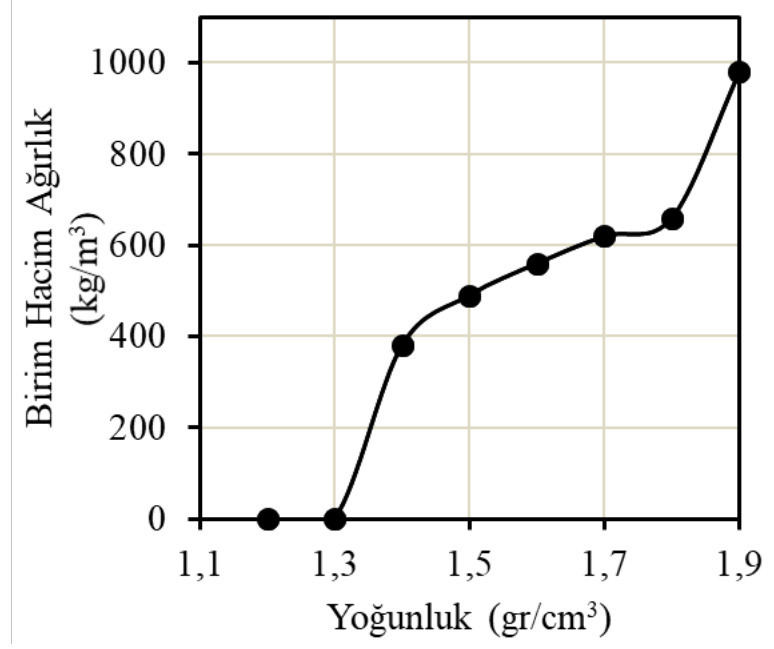

Şekil 6. $-10+4.75 \mathrm{~mm}$ tane boyutu aralı̆̆ında sınıflandırılmış pomza numunesinin yoğunluğa dayalı birim hacim ağırlık değerleri

$\mathrm{Bu}$ bağlamda çalışmanın bu aşamasında 1.2-1.8 $\mathrm{gr} / \mathrm{cm}^{3}$ yoğunluk aralığında $0.2 \mathrm{gr} / \mathrm{cm}^{3}$ yoğunluk artış oranlarına sahip 4 farklı pomza numunesi öncelikle ayrı ayrı -16 $\mathrm{mm}$ tane boyutuna kırılmış ve sonrasinda $-16+8 \mathrm{~mm},-8+4 \mathrm{~mm}$ ve $-4 \mathrm{~mm}$ tane boyutu aralıklarında sinıflandırılmıştır. Sınıflandırılan pomza numuneleri ve katkı maddeleri Tablo 6'da verilen oranlar sabit tutularak karıștırma işlemine tabi tutulmuştur.

Tablo 6. Hazırlanan yapı bloklarında kulanılan pomza ve katkı maddelerinin miktarları.

\begin{tabular}{lc}
\hline \multicolumn{1}{c}{ İçerik } & $\begin{array}{c}\text { Ağırlık } \\
(\%)\end{array}$ \\
\hline -16+8 mm pomza numunesi & 20 \\
-8+4 mm pomza numunesi & 50 \\
-4 mm pomza numunesi & 17 \\
Çimento & 8 \\
Su & 5 \\
\hline
\end{tabular}

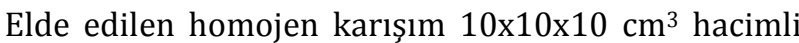
kalıplara aktarılmıştır. Daha sonra kalıplara $25 \mathrm{MPa}$ basınç altında sıkıştırma işlemi uygulanmış ve kalıplardan çıkarılan yapı blokları kurumaya bırakılmıştır (Şekil 7). 
Sonuçların yorumlanmasında $\mathrm{mW} / \mathrm{m} * \mathrm{~K}$ birimli Lambda değerleri dikkate alınmış, kuruma işlemleri sonrasında analizlere tabi tutulan yapı bloklarının termal iletkenlik değerleri Tablo 7'de verilmiștir. Sonuçlara göre en yüksek termal iletkenlik veriminin, deneysel çalışmalarda kullanılan en düşük yoğunluk (1.2 $\mathrm{gr} / \mathrm{cm}^{3}$ de yüzen) değerine sahip pomzaların kullanımı ile sağlandığı, artan pomza yoğunluğu ile birlikte termal iletkenlik değerlerinin arttığ görülmektedir. Bu değer $1.2 \mathrm{gr} / \mathrm{cm}^{3}$ çinko klorür çözeltisinde yüzen pomza numunesi için 134.6 $\mathrm{mW} / \mathrm{m} * \mathrm{~K}$ iken, artan yoğunluk ile kademeli olarak artarak $1.4 \mathrm{gr} / \mathrm{cm}^{3}$ de yüzen pomza numunesi için yaklaşı $147 \mathrm{~mW} / \mathrm{m}^{*} K^{\prime}$ ya ve $1.8 \mathrm{gr} / \mathrm{cm}^{3}$ yoğunlukta yüzen pomza numunesi için yaklaşık 197 $\mathrm{mW} / \mathrm{m} * K^{*}$ ya çıkmaktadır.



Şekil 7. Pomza numuneleri kullanılarak hazırlanan yapı bloklarl.

Tablo 7. Yapı bloklarının termal iletkenlik değerleri.

\begin{tabular}{lc}
\hline İçerik & $\begin{array}{c}\text { Termal iletkenlik } \\
\left(\mathrm{mW} / \mathrm{m}^{*} \mathrm{~K}\right)\end{array}$ \\
\hline$-1.2 \mathrm{gr} / \mathrm{cm}^{3}$ pomza & 134.6 \\
$-1.4+1.3 \mathrm{gr} / \mathrm{cm}^{3}$ pomza & 146.9 \\
$-1.6+1.5 \mathrm{gr} / \mathrm{cm}^{3}$ pomza & 162.3 \\
$-1.8+1.7 \mathrm{gr} / \mathrm{cm}^{3}$ pomza & 196.5 \\
\hline
\end{tabular}

\section{Tartışma ve Sonuç}

$-50+4.75 \mathrm{~mm}$ boyut aralığında 4 farklı boyutta sınıflandırılmış pomza örnekleri kullanılarak çinko klorür çözeltileri kullanılarak gerçekleştirilen laboratuvar ölçekli yüzdürme-batırma test sonuçlarına göre $1.8 \mathrm{gr} / \mathrm{cm}^{3}$ den daha yüksek yoğunluklara sahip numune miktarı her bir dar tane boyut aralı̆̆ı için \% 29-37 arasında değişmiştir.

Azalan tane boyutu ile birlikte pomza tanelerinin gözeneklilik oranları doğru orantılı olarak azalmıș, sonuç olarak küçülen tane boyutu ile birlikte 1.2 $\mathrm{gr} / \mathrm{cm}^{3}$ ten daha hafif (yüzen) pomza numunelerinin miktarı da azalmıştır. En iri tane boyutu olan $-50+25$ $\mathrm{mm}$ tane boyutu aralığında $1.2 \mathrm{gr} / \mathrm{cm}^{3}$ yoğunluklu çinko klorür çözeltisinde yüzen pomza miktarı beslemenin yaklaşık \%11.2'si iken, küçülen tane boyutu ile birlikte bu değer $-25+15 \mathrm{~mm}$ tane boyutlu pomza numunesi için \%7'ye, $-15+10 \mathrm{~mm}$ tane boyutlu pomza numunesi için ise \%1'e kadar düşmüştür. 10 mm'den daha küçük tane boyutlarında ise 1.2-1.3 $\mathrm{gr} / \mathrm{cm}^{3}$ yoğunluklarda yüzen pomza numunesi elde edilememiştir.

Deneysel sonuçlara göre en düşük birim hacim ağırlık değerleri $1,2 \mathrm{gr} / \mathrm{cm}^{3}$ yoğunluklu çinko klorür çözeltisinde yüzen pomza numunelerinden 350 $\mathrm{kg} / \mathrm{m}^{3}$ ten daha düşük değerler olarak elde edilmiş olup, artan pomza yoğunluğu ile kademeli olarak artarak $1000 \mathrm{gr} / \mathrm{cm}^{3} \mathrm{e}$ kadar ulaşmıştır.

Termal iletkenlik analiz sonuçlarına göre ise en iyi termal iletkenlik değerleri en düşük yoğunluklu pomza numuneleri kullanılarak oluşturulan yapı blokları ile elde edilmiştir. Artan pomza yoğunluğu ile termal iletkenlik özelliği artarken, en yüksek termal iletkenlik değeri $1.8 \mathrm{gr} / \mathrm{cm}^{3}$ yoğunluklu çinko klorür çözeltisinde yüzen pomza numunesi ile elde edilmiştir.

Elde edilen sonuçlara göre zenginleştirme işlemleri uygulanarak elde edilecek düşük yoğunluklu pomza numuneleri kullanılarak daha yüksek termal yalıtım özellikleri sunabilecek yapı bloklarının üretilebileceği sonucu çıkarılmıştır.

\section{Teşekkür}

Deneysel çalışmalarda kullanılan pomza numunesinin temini ve termal iletkenlik ölçümleri için kolaylıklar sağlayan ISBAȘ A.Ș. Genel Müdürü İ.Gürakan'a, deneysel çalışmalar ve numune hazırlama ișlemlerinde yardımlarını esirgemen M.A.Türkmen, K.Şimşek ve A.Cerit'e teşekkür ederim.

\section{Kaynakça}

[1] Presyley, G.C., 2006. Pumice, Pumicite And Volcanic Cinder, Industrial Minerals And Rocks; Commodities, Markets And Uses (7th edition), 743-754.

[2] Adams, J.A., 1941. Pumice and pumicite, GMI Short Paper, No:6, State of Oregon, Department of Geology and Mineral Industries.

[3] Ersoy, B., Sarışık, A., Dikmen, S., Sarışık, G., 2010. Characterization of acidic pumice and determination of its electrokinetic properties in water, Powder Technology vol.197, 129-135.

[4] Karaipekli, A., Sarı, A., 2016. Development and thermal performance of pumice/organic PCM/gypsum composite plasters for thermal energy storage in buildings. Solar Energy Materials \& Solar Cells vol.149, 19-28.

[5] TS 3234/T1, 1983. Bimsbeton yapım kuralları, karışım hesabı ve deney metotları, TSE, Ankara.

[6] Geitgey, R.P., 1994. Industrial Minerals and Rocks, 6.th Edition, Society for Mining, Metalurgy and Exploration, Inc. Littleton, s.803813, Colorado.

[7] Aksay Kilinc, E., 2005. Izmir-menderes yöresi pomza cevherinin kullanımına yönelik teknolojik özelliklerinin araştırılması, Doktora Tezi, Fen Bilimleri Enstitüsü, Dokuz Eylül Üniversitesi, s.278, İzmir. 
[8] Dinçer, İ., Orhan, A., Çoban, S., 2015. Ahiler Kalkınma Ajansı; Pomza araştırma ve uygulama merkezi fizibilite raporu, Nevşehir Hacı Bektaș Veli Üniversitesi, Jeoloji Mühendisliği Bölümü, Nevşehir.

[9] Doğan-Sağlamtimur, N., Güven, A., Bilgil, A., 2018. Physical and mechanical properties of cemented ash-based lightweight building materials with and without pumice, Advances in Materials Science and Engineering, vol. 2018, Article ID 9368787.

[10] Gündüz, L., 1998. Pomza Teknolojisi, Cilt 1, 285 s, Isparta.

[11] Aksay Kılınç, E., Cöcen, İ., Akar, A., 2016. Pomzanın su arıtımında filtre malzemesi olarak kullanımındaki gelişmeler, DPÜ Fen Bilimleri Enstitüsü Dergisi 36, 63-72.

[12] Deniz, V., Umucu, Y., Çayırlı, S., 2012. Estimation of the bond grindability index from the sink-float test data of two different particulate pumices,
Particulate Science and Technology, 30(5), 403415.

[13] Karaipekli, A., Sarl, A., 2016. Development and thermal performance of pumice/organic PCM/gypsum composite plasters for thermal energy storage in buildings, Solar Energy Materials \& Solar Cells, 149, 19-28.

[14] Uysal, H., Demirboga, R., Sahin, R., Gul, R., 2004. The effects of different cement dosages, slumps, and pumice aggregate ratio on the thermal conductivity and density of concrete, Cement and Concrete Research, 34(5), 845-848.

[15] Demirboga, R., Gul, R., The effects of expendad perlite aggregate, silica füme and fly ash on the thermal conductivity of lightweight concrete, Cement and Concrete Research, 33(5), 723-727.

[16] Idris, I.H.M., Yusof, N.Z., 2018. Development of low thermal mass cement-sand block utilizing peat soil and effective microorganism, Case Studies in Construction materials 8, 8-15. 